\title{
Pênfigo Foliáceo Endêmico (Fogo Selvagem) e sua associação com fatores ambientais e ocupacionais em Ouro Preto, Minas Gerais, Brasil
}

\author{
Endemic Pemphigus Foliaceus (Fogo Selvagem) and its \\ association with environmental and occupational factors in \\ Ouro Preto, Minas Gerais, Brazil
}

\author{
Olívia Maria de Paula Alves Bezerra', Márcio Antonio Moreira Galvão', \\ Danilo Jorge da Silva', Cássia Rafaela Leão de Brito², \\ Mariana Carla Santos Rossini ${ }^{3}$, Pedro Marcos Silva e Gonçalves ${ }^{4}$, \\ Lorena de Souza Bueno ${ }^{5}$, Anelise Andrade de Souza ${ }^{6}$
}

\begin{abstract}
Resumo
Pênfigo compreende grupo de doenças bolhosas autoimunes que possuem tendência à progressão, com evolução ilimitada e crônica e com prognóstico potencialmente fatal. O tipo mais comum é o Pênfigo Foliáceo Endêmico (PFE), caracterizado pela presença de lesões cutâneas com formação de bolhas na face, no couro cabeludo e na região interescapular. Fatores de ordem ambiental, genéticos e imunológicos podem desencadear a enfermidade. Entre os fatores ambientais, exposição a mercúrio, poeiras minerais e a picada do mosquito Simulium nigrimanum devem ser considerados. Buscou-se, neste artigo, relatar a ocorrência do PFE entre a população de Antônio Pereira, distrito rural de Ouro Preto, Minas Gerais, bem como identificar possíveis associações da doença com fatores ocupacionais e ambientais locais. Foi constatada uma prevalência de 4,57 casos de PFE/1.000 habitantes, considerada bastante elevada. Observou-se associação estatística entre a doença e contato com barragem de rejeitos de mineração $(p=0,048)$ e exposição ao mercúrio $(p=0,008)$. Os resultados indicam a necessidade de vigilância epidemiológica eficaz das comunidades afetadas, assim como adequada assistência à saúde dos pacientes acometidos pela doença.
\end{abstract}

Palavras-chave: pênfigo foliáceo endêmico; fatores ambientais e ocupacionais; mineração; mercúrio; barragem de rejeito.

\section{Abstract}

Pemphigus comprises a group of autoimmune bullous diseases, which have a tendency of progression, with unlimited and chronic development and with a potentially to fatal disease prognosis. The most common type is the Endemic Pemphigus Foliaceus (EPF), characterized by the presence of skin lesions with blistering located on the face, scalp and interscapular region. Environmental,

'Escola de Medicina, Universidade Federal de Ouro Preto (UFOP) - Ouro Preto (MG), Brasil.

${ }^{2}$ Setor de Clínica Médica, Hospital da Polícia Militar de Minas Gerais - Belo Horizonte (MG), Brasil.

${ }^{3}$ Hospital das Clínicas, Universidade Federal do Triângulo Mineiro (UFTM) - Uberaba (MG), Brasil.

${ }^{4}$ Departamento de Anestesiologia, Hospital Unimed - Belo Horizonte (MG), Brasil.

5Universidade Federal de Santa Catarina (UFSC) - Florianópolis (SC), Brasil.

${ }^{6}$ Escola de Nutrição, Universidade Federal de Ouro Preto (UFOP) - Ouro Preto (MG), Brasil.

Trabalho realizado na Universidade Federal de Ouro Preto (UFOP) - Ouro Preto (MG), Brasil.

Endereço para correspondência: Olívia Maria de Paula Alves Bezerra - Escola de Medicina, Universidade Federal de Ouro Preto (UFOP), Campus Universitário, Morro do Cruzeiro - CEP: 35400-000 - Ouro Preto (MG), Brasil - Email: ompab@yahoo.com.br

Fonte de financiamento: Universidade Federal de Ouro Preto.

Conflito de interesses: nada a declarar. 
genetic and immunological factors may trigger the disease. Among the environmental factors, exposure to mercury, mineral dust and Simulium nigrimanum mosquitoes bite should be considered. Sought to, in this article, it is reported the occurrence of PFE among the population of Antonio Pereira, rural district of Ouro Preto, Minas Gerais, and identify their possible association with occupational and environmental local factors. A prevalence of 4.57 cases of EPF/1.000 inhabitants, considered high was found. There was association between the disease and contact with dam tailings mining $(p=0.048)$; and exposure to mercury $(p=0.008)$. The results indicate the need for effective surveillance of the affected communities, as well as adequate health care of patients affected by the disease.

Keywords: endemic pemphigus foliaceus; environmental and occupational factors; mining; mercury; tailings dam.

\section{INTRODUÇÃO}

Pênfigo compreende um grupo de doenças imunomediadas, com afecção cutânea, que cursam com a presença de bolhas intra-epidérmicas ${ }^{1-4}$. Uma das características típicas da doença é a presença de autoanticorpos IgG contra a superfície celular dos acantócitos ${ }^{2,4}$. Os autoanticorpos presentes nessas doenças reagem com as moléculas de adesão celular, levando à acantólise e resultando em perda de coesão entre os queratinócitos, o que leva à formação das vesículas e bolhas².

Os tipos de pênfigo estão classificados em diferentes variantes clínicas e etiopatogênicas, dentre elas o pênfigo foliáceo e o pênfigo vulgar $^{2}$. Enquanto o pênfigo foliáceo apresenta autoanticorpos contra desmogleínal (anti-dsg1) ${ }^{4,5}$, o pênfigo vulgar caracteriza-se pela presença de anticorpo antidesmogleína 3 (anti-dsg3) na forma mucosa e de anti-dsg1 e 3 na forma mucocutânea ${ }^{3,6}$.

O pênfigo foliáceo $(\mathrm{PF})$ pode ser subdividido em clássico ou doença de Cazenave, e endêmico ou fogo selvagem (PFE), cuja endemicidade está presente no Brasil, entre as longitudes $45^{\circ}$ e $60^{\circ}$ oeste e latitudes $5^{\circ}$ e $25^{\circ}$ sul, em altitudes que variam entre 500 e 800 metros $^{7}$. Foram descritos focos no Distrito Federal e nos estados de Goiás, Mato Grosso, Mato Grosso do Sul, Tocantins, Minas Gerais, Paraná e São Paulo, com etiologia ainda desconhecida ${ }^{7}$

A doença geralmente tem início no segmento cefálico, com progressão crânio caudal simétrica e preferência pelo couro cabeludo, face, tórax e costas, raramente atingindo mucosas ${ }^{4}$. A existência da forma endêmica de doença autoimune é incomum, sendo esta uma das características marcantes do pênfigo foliáceo ${ }^{5}$.

Tipicamente, a doença se manifesta em crianças e jovens, com pico de incidência entre a segunda e terceira décadas de vida ${ }^{6}$, e afeta igualmente homens e mulheres ${ }^{2}$. Nas áreas endêmicas, sua incidência é bastante elevada, com cerca de 25 casos por milhão de habitantes por ano ${ }^{7}$.

Na patogenia do PFE devem ser considerados fatores genéticos, imunológicos e ambientais, os quais podem desencadear a enfermidade ${ }^{6,7}$. Sua própria endemicidade, com a existência de focos geograficamente definidos, demonstra a importância de fatores ambientais nesse desencadeamento: os doentes são habitualmente lavradores ou familiares deles que vivem em más condições sociais, em habitações precárias próximas a córregos, com higiene precária, em meio a animais domésticos e grande quantidade e variedade de insetos ${ }^{6}$.

$\mathrm{Na}$ literatura, diversos fatores ambientais são apontados como possíveis desencadeadores da resposta autoimune causadora da doença, tais como exposição a mercúrio, picada do mosquito Simulium nigrimanum, popularmente conhecido como borrachudo, exposição a poeiras minerais e uso de drogas contendo um radical sulfidril (como penicilamina e captopril) ${ }^{3}$.

Quanto aos aspectos clínicos do PFE, mesmo se tratando de um tipo de dermatite bolhosa, bolhas intactas geralmente não são constatadas, devido a sua extrema superficialidade. Os pacientes geralmente apresentam múltiplas erosões crostosas sobre base eritematosa, ou ceratose seborreica. Devido à sensação de queimação que piora com o calor ou exposição solar, surgiu o termo fogo selvagem ${ }^{1}$.

A doença pode ocorrer na forma localizada, na qual o tratamento com corticóides tópicos pode ser suficiente; e na forma generalizada, em que as lesões se disseminam no sentido craniocaudal e podem evoluir com eritema descamativo, caracterizando a forma eritrodérmica ${ }^{2}$. O tratamento com $1 \mathrm{mg} / \mathrm{kg} /$ dia de prednisona na maioria das vezes logra bons resultados. Pode-se associar ainda medidas como uso de carbonato de cálcio, complemento de vitamina $\mathrm{D}$ e vaselina tópica e evitar exposição ao sol. Em casos graves, um imunossupressor pode ser necessário ${ }^{1}$.

O distrito de Antônio Pereira, pertencente ao município de Ouro Preto, Minas Gerais, está localizado a aproximadamente $14 \mathrm{~km}$ da sede e a $130 \mathrm{~km}$ da capital do estado, Belo Horizonte. Trata-se de um pequeno distrito rural cuja população, segundo dados da unidade de saúde local, é de aproximadamente 3.500 habitantes. A principal atividade econômica do distrito gira em torno da extração e beneficiamento de minério de ferro, estando duas grandes empresas mineradoras situadas em suas proximidades. Uma barragem de rejeitos de uma delas, conhecida como barragem de Doutor, ativada, está localizada a montante de Antônio Pereira e acumula rejeitos da atividade de exploração do minério de ferro (Figura 1).

Também ocorrem atividades informais relacionadas ao garimpo de ouro e gemas na localidade, com utilização de mercúrio para formação de amálgama, visando a separação do ouro do minério. 


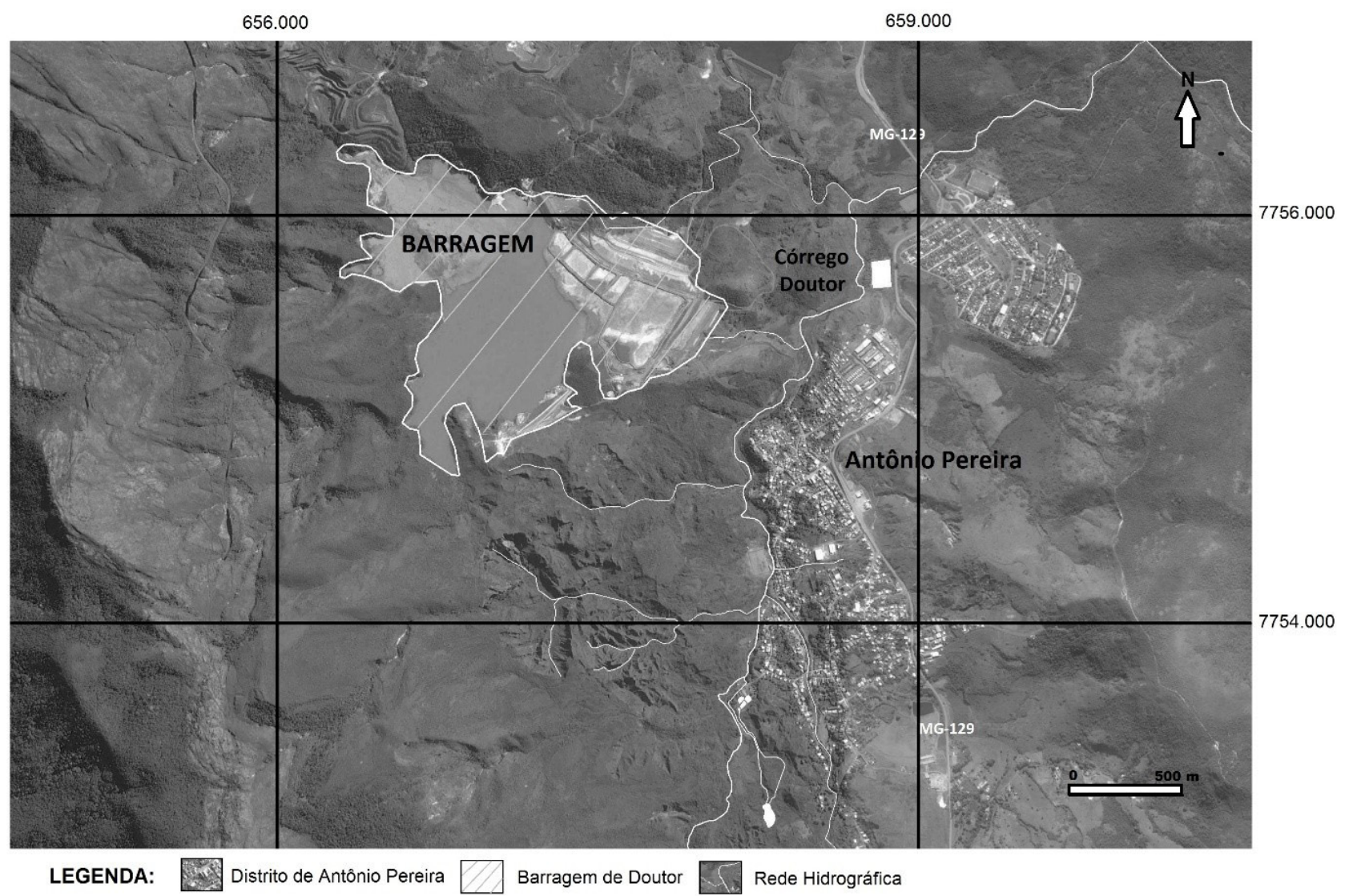

Figura 1. Imagem da região do Distrito de Antônio Pereira. Fonte: Google Earth

Buscou-se, neste artigo, relatar a ocorrência do PFE entre a população de Antônio Pereira, localidade em que a doença ainda não havia sido identificada, bem como identificar suas possíveis associações com fatores ocupacionais e ambientais.

\section{METODOLOGIA}

Trata-se de um estudo transversal realizado com portadores de PFE residentes no distrito de Antônio Pereira, Ouro Preto, MG. Os portadores foram identificados por meio de busca ativa, após identificação de um caso-índice acompanhado em 2013 na Unidade Básica de Saúde (UBS) local. As informações clínicas foram colhidas entre 2013 e 2015, a partir dos prontuários médicos e dos exames laboratoriais anexados a eles. Exames clínicos foram efetuados a fim de caracterizar a evolução da doença.

Foram incluídos no estudo a totalidade dos indivíduos residentes em Antônio Pereira que apresentavam diagnóstico comprovado da doença (por meio de biópsias e outros exames laboratoriais e/ou clínicos) no período estudado, e que aceitaram participar voluntariamente mediante assinatura de Termo de Consentimento Livre e Esclarecido (TCLE). Este grupo foi denominado Portadores.

Um segundo grupo foi formado para fins de comparação, composto por indivíduos não portadores de PFE ou outras doenças dermatológicas, pertencentes à mesma família e residentes no mesmo domicílio dos portadores e que aceitaram participar voluntariamente do estudo. Este grupo foi denominado Não Portadores.

Por meio de entrevistas individuais, foi aplicado um questionário pré-validado em estudo piloto aos dois grupos, durante consultas médicas ou visitas domiciliares, sendo colhidos dados socioeconômicos e demográficos, história clínico-ocupacional e de exposição ambiental a agentes possivelmente associados ao PFE. As variáveis analisadas foram:

a) Contato com barragem de rejeitos de mineração: Incluiu as formas de contato ocupacionais e ambientais diretas e não ocasionais com barragem de rejeitos.

b) Contato com poço ou córrego em proximidades de barragem de rejeitos: Incluiu a exposição ambiental não ocasional a poços ou córregos nas proximidades da barragem de rejeitos ou que recebem detritos dessa barragem.

c) Exposição ao mercúrio: Incluiu as formas de contato ocupacionais e ambientais não ocasionais com o mercúrio utilizado na formação de amálgama com ouro.

d) Exposição ao minério de ferro: Incluiu as formas de contato ocupacionais e ambientais não ocasionais com a poeira do minério de ferro. Foram incluídos neste grupo indivíduos que trabalham nas etapas de extração, beneficiamento direto e manipulação 
de maquinário em estações de trabalho em que há produção de poeira de minério de ferro, localizadas em mineradoras. Além desses indivíduos, foram incluídos aqueles em contato domiciliar frequente com poeira arrastada pelo vento proveniente de áreas de mineração (contato ambiental).

e) Histórico de trabalho em mineradora: Incluiu a história atual ou pregressa de qualquer atividade laboral exercida no espaço físico de mineradoras da região, em atividades como extração, beneficiamento, transporte de minério ou rejeitos, limpeza de áreas ou equipamentos nas áreas de produção, além do trabalho em refeitórios próximos a áreas de produção.

f) Exposição ocupacional à sílica: Incluiu a exposição ocupacional à poeira de sílica em outros ambientes que não os da mineração, como, por exemplo, a construção civil. Foram considerados não expostos os indivíduos que alegaram contato exclusivo com a poeira domiciliar comum (atividades de faxina em localidades residenciais).

Definiu-se como forma de contato ocupacional direto: manipulação, inalação, processamento por meio de maquinário e ferramentas ou outras formas de exposição objetiva da pele, mucosas ou vias aéreas ao agente, seja no exercício de atividades laborais oficiais ou para renda complementar - foram incluídas neste grupo pessoas que manipulam mercúrio armazenado em ambiente domiciliar para extração artesanal de ouro. Para as formas de contato ambiental direto definiu-se a exposição a lâmina de água potencialmente poluída com os agentes selecionados (poço ou córrego em proximidades de barragem de rejeitos e áreas de garimpo artesanal de ouro e queima de amálgama), a poeira ou agentes químicos/minerais em atividades de lazer, limpeza doméstica ou por habitar nas proximidades de fontes de exposição (como atividades de mineração em peridomicílio). Atividades de pesca não comercial em veios potencialmente expostos também foram incluídas neste grupo. Considerou-se como contato não ocasional aquele com período mínimo de 12 meses contíguos e frequência mínima de contato semanal nesse período (somando-se as atividades desenvolvidas em um mesmo ambiente no cálculo da frequência de exposição ambiental - exemplo: pesca, banho recreativo e lavagem de roupa em córrego em proximidades de barragem de rejeitos).

Os dados obtidos foram analisados pelos testes $t$ bicaudal e exato de Fisher no programa SPSS Statistics 17.0 ao nível de significância de $5 \%$, e as médias foram expressas seguidas pelo respectivo desvio padrão. $\mathrm{O}$ estudo foi aprovado pelo Comitê de Ética em Pesquisas da Universidade Federal de Ouro Preto (CAAE 25580413.1.0000.5150) e não apresenta conflito de interesses.

\section{RESULTADOS}

Observou-se prevalência de PFE de 4,57/mil habitantes em Antônio Pereira no período em estudo, correspondente aos anos de 2013 a 2015. A média da renda familiar observada para os grupos Portadores e Não Portadores da doença foi de
$\mathrm{R} \$ 1.675,69 \pm 1.031,69$. A distribuição dos portadores de PFE segundo o sexo mostrou-se homogênea, sendo 8 homens e 8 mulheres, todos em acompanhamento na Unidade Básica de Saúde (UBS) local. A idade neste grupo variou de 11 a 66 anos, com média de 30,9 $\pm 16,6$ anos, e a escolaridade média, dada em anos completos de estudo, foi de 7,94 $\pm 3,21$ anos (Figuras 2A, B).

O grupo Não Portadores da doença foi composto pelos 6 homens e 7 mulheres que aceitaram participar do estudo. Sua idade média era de 42,0 $\pm 13,2$ anos e a escolaridade média, de 7,92 $\pm 3,30$ anos (Figuras 2A, B), sendo que nenhum desses resultados apresentou diferenças estatísticas em relação ao grupo de Portadores ( $\mathrm{p}>0,05)$.

Todos os indivíduos declararam ter acesso aos serviços públicos de saúde e $23,1 \%$ do grupo Não Portadores alegou possuir plano privado de saúde, contra $56,3 \%$ no grupo Portadores (Figura 2C). O acesso a plano privado de saúde não constituiu associação significativa com PFE (teste exato de Fisher, $\mathrm{p}=0,067$ ).

As condições de moradia e de saneamento básico observadas revelaram domicílios em alvenaria com acesso a água potável encanada, esgotamento sanitário e coleta domiciliar de lixo para todos os participantes do estudo.

As atividades exercidas pelos portadores na data da entrevista eram: estudantes (3), donas de casa (4), armador (1), pedreiro (1), técnico em segurança do trabalho (1), sinaleiro (1), supervisor mecânico (1), manicure (1), desempregado (2) e não informado (1). Três deles trabalhavam em áreas de extração de minério de ferro da região (armador, sinaleiro e supervisor mecânico). As atividades exercidas pelos integrantes do grupo Não Portadores eram: comerciante (1), donas de casa (2), estudante (1), diarista (1), soldador (1), coletor de eucalipto (1), mecânico industrial (1) e policial reformado (1); os demais se encontravam desempregados (4). As quatro últimas atividades ocupacionais de todos os entrevistados (portadores e não portadores) também foram analisadas em busca de exposições ocupacionais pregressas aos fatores de risco elencados entre as variáveis de estudo.

Dentre os indivíduos portadores de PFE, 5 alegaram contato com barragem de rejeitos de mineração $(31,25 \%)$, contra nenhum do grupo Não Portadores, fator associado significativamente ao risco para a doença $(p=0,048)$. Contudo, não se observou associação significativa $(p=0,702)$ entre contato com poço ou córrego em proximidades de barragem de rejeitos, com 7 indivíduos no grupo Portadores confirmando exposição (43,75\%) contra 4 do grupo Não Portadores (30,76\%). Exposição ao mercúrio foi confirmada por $9(56,25 \%)$ dos portadores de PFE, contra apenas um indivíduo confirmado do grupo Não Portadores (o qual exerceu atividade como garimpeiro na região), tendo a exposição ao mercúrio se configurado como medida significativa de risco $(\mathrm{p}=0,008)$. Entretanto, exposição ao minério de ferro 

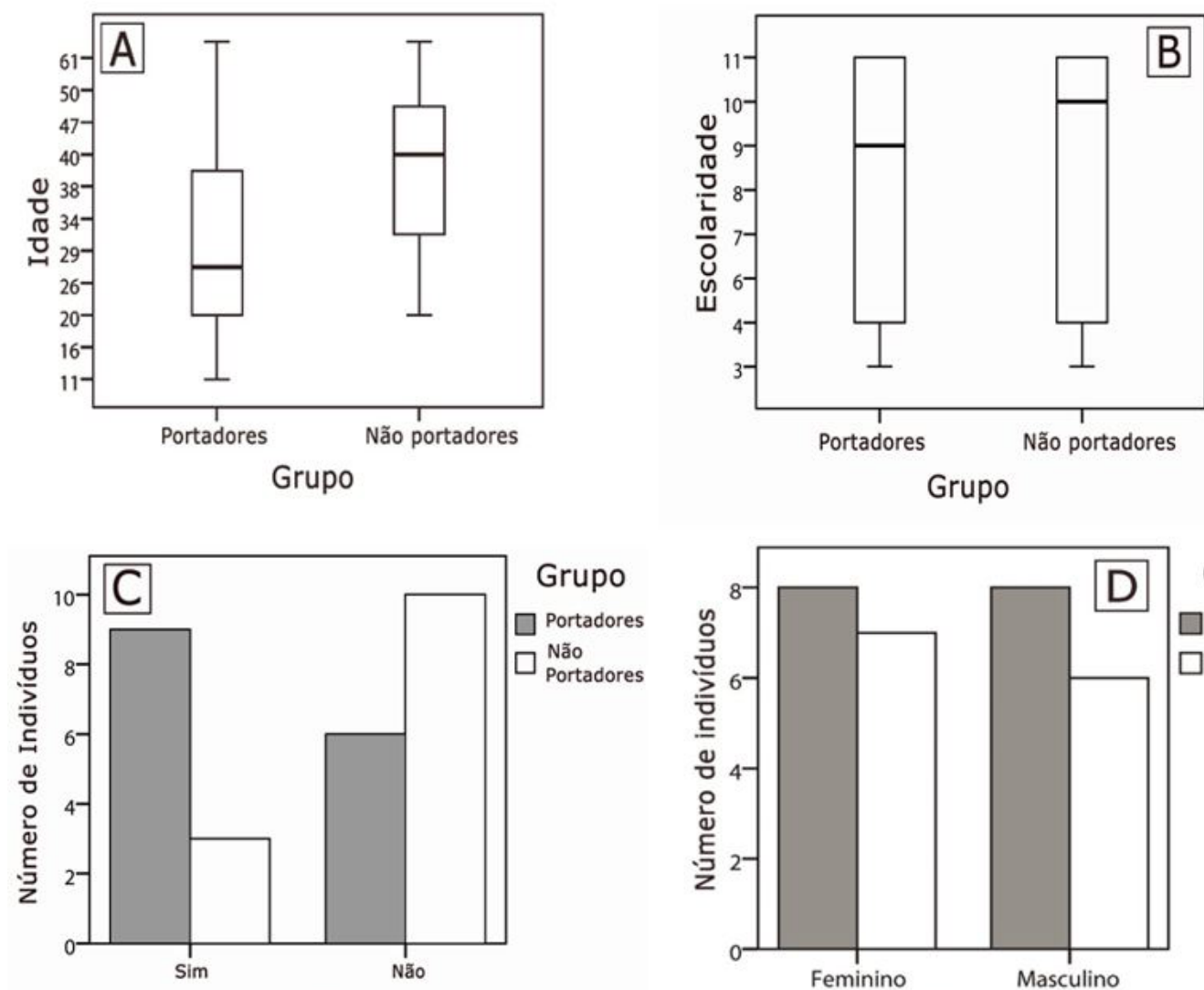

Plano de Saúde

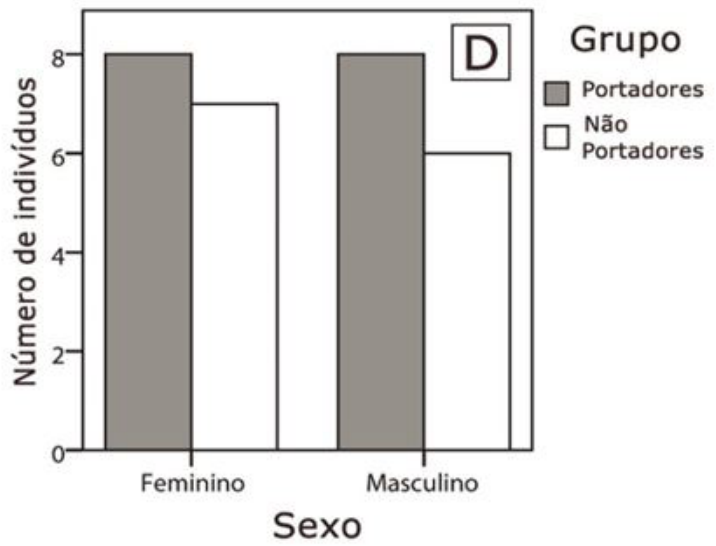

Figura 2. Distribuição de idade, escolaridade, acesso a plano privado de saúde e sexo. (A) Distribuição de idade segundo portadores e não portadores de PFE $(p=0,37 ; n=29)$; (B) Distribuição de escolaridade segundo portadores e não portadores de PFE ( $p=0,57 ; n=29$ ); (C) Distribuição de indivíduos conforme acesso a plano privado de saúde, segundo portadores e não portadores de $P F E(n=28, p=0,06)$; (D) Distribuição de indivíduos conforme sexo, segundo portadores e não portadores de PFE $(n=29 ; p=0,84)$

e exposição ocupacional à sílica não apresentaram associação estatisticamente significativa ( $\mathrm{p}>0,05)$, embora caiba ressaltar que um maior percentual de indivíduos do grupo Portadores confirmou exposição a esses agentes quando comparados ao grupo Não Portadores. Dentre os portadores de PFE, 50\% apresentaram histórico de trabalho em mineradora em algum momento da vida, com um percentual observado no grupo Não Portadores de 38,46\% dos entrevistados. Entretanto, não se observou associação significativa entre esse histórico e PFE $(p=0,711)$. Esses dados encontram-se sumarizados na Tabela 1.

A história patológica pregressa e atual no grupo controle não evidenciou casos de doenças do aparelho respiratório, atopias (de nenhuma natureza) ou doenças de base autoimune. No grupo Portadores constatou-se história pregressa de asma em um indivíduo e história atual de rinite alérgica em outro participante do estudo.

\section{DISCUSSÃO}

Poucos autores realizaram levantamentos da prevalência de casos de PFE no Brasil. Estudo de busca ativa em bancos de dados hospitalares, de clínicas dermatológicas e centros de referência em dermatologia no Estado de Minas Gerais desenvolvido por Pimentel et al. entre 2005 e 2006 estima prevalência de 1,22 casos para cada 100 mil habitantes, ou 0,012 caso a cada mil habitantes ${ }^{8}$. O número de pacientes identificados no presente estudo em Antônio Pereira, também em busca ativa, revelou 4,57 casos para cada mil habitantes em acompanhamento na unidade básica de saúde local, valor que supera sobremaneira a prevalência estimada para o estado por Pimentel ${ }^{8}$.

A não observação de disparidades em relação ao sexo está em conformidade com achados da literatura ${ }^{9-11}$, embora alguns autores admitam que há ligeira predominância do sexo feminino entre os portadores dessa forma de pênfigo ${ }^{12}$.

Como doença de caráter multifatorial, inúmeras propostas de fatores ambientais de risco são citadas na literatura como associadas ao PFE. Tradicionalmente, são descritas a exposição à picada de mosquito do gênero Simulium nigrimanum ${ }^{13}$ (conhecido popularmente como borrachudo) e o pertencimento a região rural como fatores de risco associados ao $\mathrm{PFE}^{12,14}$. Entretanto, a relação entre vetores e possíveis fatores etiológicos ainda não é clara e pode incluir roedores e outras espécies de insetos hematófagos, bem como outras espécies do gênero Simulium, 
Tabela 1. Fatores de exposição ambiental e ocupacional para PFE segundo grupo de estudo

\begin{tabular}{|c|c|c|c|c|c|}
\hline \multirow[b]{2}{*}{ Exposição (forma) } & & \multicolumn{2}{|c|}{ Grupo } & \multirow[b]{2}{*}{ Total } & \multirow[b]{2}{*}{$\mathbf{P}$} \\
\hline & & $\begin{array}{l}\text { Portadores de } \\
\text { PFE }\end{array}$ & $\begin{array}{l}\text { Não Portadores } \\
\text { de PFE }\end{array}$ & & \\
\hline \multirow{2}{*}{ Contato com barragem de rejeitos de mineração $(\mathrm{T})$} & Não & 11 & 13 & 24 & \multirow[t]{2}{*}{$0,048^{*}$} \\
\hline & Sim & 5 & 0 & 5 & \\
\hline \multirow{2}{*}{$\begin{array}{l}\text { Contato com poço ou córrego em proximidades de } \\
\text { barragem de rejeitos (A) }\end{array}$} & Não & 9 & 9 & 18 & \multirow[t]{2}{*}{0,702} \\
\hline & Sim & 7 & 4 & 11 & \\
\hline \multirow{2}{*}{ Exposição a mercúrio (T) } & Não & 7 & 12 & 19 & \multirow[t]{2}{*}{$0,008^{\star}$} \\
\hline & Sim & 9 & 1 & 10 & \\
\hline \multirow{2}{*}{ Exposição a minério de ferro $(\mathrm{T})$} & Não & 6 & 7 & 13 & \multirow[t]{2}{*}{0,467} \\
\hline & $\operatorname{Sim}$ & 10 & 6 & 16 & \\
\hline \multirow{2}{*}{ Histórico de trabalho em mineradora $(\mathrm{O})$} & Não & 8 & 8 & 16 & \multirow[t]{2}{*}{0,711} \\
\hline & $\operatorname{Sim}$ & 8 & 5 & 13 & \\
\hline \multirow{2}{*}{ Exposição ocupacional a sílica (O) } & Não & 6 & 8 & 14 & \multirow[t]{2}{*}{0,272} \\
\hline & Sim & 10 & 5 & 15 & \\
\hline
\end{tabular}

$\mathrm{P}$ - valor de p para o teste exato de Fisher; ${ }^{*}$ Resultado significativo ao nível de significância de 5\%; Formas de contato: $\mathrm{A}=$ ambiental; $\mathrm{O}=$ ocupacional; $\mathrm{T}=$ total (ocupacional + ambiental); PFE - Pênfigo Foliáceo Endêmico

como S. pertinax ${ }^{13}$ e $S$. pruinosum ${ }^{9}$. No presente estudo não foi analisada a exposição ao mosquito Simulium nigramanum, posto que a espécie não foi formalmente identificada na região. Além disso, é esperada exposição relativamente homogênea a insetos hematófagos locais entre membros dos grupos Portadores e Não Portadores, já que os indivíduos coabitam os mesmos domicílios em região rural de pequena dimensão.

Alguns autores ainda consideram que condições precárias de moradia, como casas de pau a pique, estão elencadas como prováveis fatores de risco ${ }^{14}$. Essas condições, todavia, não explicam a elevada prevalência de PFE observada em Antônio Pereira, uma vez que os dois grupos estudados se encontram em situação semelhante de moradia (todos em casas de alvenaria) e que portadores e não portadores da doença são de mesma família e coabitam os mesmos domicílios. Os dois grupos apresentaram, também, acesso semelhante a saneamento básico: rede coletora de esgoto, água encanada e coleta de lixo, não sendo possível verificar se há maior prevalência de PFE relacionada a más condições sanitárias.

Uma das características marcantes do distrito de Antônio Pereira é a relação estreita de sua população com atividades minerárias instaladas na região. Além da extração do minério de ferro por grandes empresas mineradoras, destacam-se as atividades informais de garimpo de ouro, historicamente desenvolvidas na localidade. Essas atividades constituem a base da economia local e são as principais responsáveis pela geração de empregos e renda. Outro dado importante é que a população desse distrito vive próxima a uma barragem de rejeitos de mineração (barragem de Doutor), sendo que os resultados deste estudo mostraram associação significativa entre o PFE e esse fator ambiental/ocupacional, o que sugere uma possível correlação entre exposição a rejeitos minerais e a manifestação da doença autoimune em indivíduos predispostos.

Outra associação significativa observada no estudo foi com a exposição a mercúrio. Segundo relatos de moradores, em Antônio Pereira alguns garimpeiros utilizam o mercúrio para a formação de amálgama com o ouro, sendo comum a estocagem do metal ou mesmo a queima de amálgamas em domicílios. A relação desse metal com o PFE é descrita em revisão elaborada por Abréu (1996), que propõe o contato com mercúrio como possível fator desencadeante ${ }^{9}$. Alterações causadas pela intoxicação por mercúrio - que incluem aumento na expressão de moléculas de MHC de classe II em linfócitos B, aumento na atividade de interleucina 4, diminuição na produção de interleucina 2 e hiperimunoglobulinemia E e G1 - levariam a um padrão de ativação de células T do tipo Th2, com uma alteração no perfil da resposta imune e na apresentação antigênica que pode desencadear eventos de autoimunidade $\mathrm{e}^{1,9,15,16}$.

No entanto, ainda que os mecanismos propostos não sejam consensuais, sabe-se que a presença de metais pesados (como mercúrio) podem desencadear síndromes autoimunes em modelos experimentais ${ }^{15-17}$. Além disso, estudo anterior também revelou níveis significativamente maiores de mercúrio em portadores de PFE em relação aos controles - detectados em cabelo, unhas ou urina - dados coerentes com a associação significativa encontrada entre exposição a mercúrio e portadores de PFE em Antônio Pereira ${ }^{15}$. O processo de bioacumulação do metilmercúrio na fauna e flora de rios sujeitos a poluição com o mercúrio e sua associação com focos endêmicos para PFE é outra hipótese que tem sido considerada em revisões da fisiopatologia e epidemiologia da doença ${ }^{1}$. Cabe ressaltar que 
a relação entre predisposição genética e exposição a múltiplos agentes está relacionada à manifestação do $\mathrm{PFE}^{6,7}$.

Embora não se tenha observado associação significativa entre o trabalho em mineradoras e a presença de PFE, há que se considerar que o estudo não se limitou a incluir apenas os envolvidos diretamente nas atividades de extração e beneficiamento de minério de ferro: atividades como transporte e manutenção de veículos dessas empresas em áreas de extração mineral também foram incluídas, e os resultados são sugestivos de que a exposição indireta em atividades de mineração não parece se associar de forma estreita aos casos de PFE observados. Não obstante, vale lembrar que a exposição aos rejeitos ocorre entre trabalhadores de mineradoras, porém não constitui risco exclusivo dessa classe.

Há que se considerar, ainda, que a ampliação do espaço amostral em futuros estudos na região de Antônio Pereira pode colaborar para esclarecer melhor a exposição a outros fatores ambientais e ocupacionais não estudados ou para os quais não foram encontradas associações estatisticamente significativas, bem como corroborar os resultados observados neste estudo.

\section{CONCLUSÕES}

Os achados deste estudo indicam uma prevalência elevada do PFE no distrito de Antônio Pereira, permitindo caracterizá-lo como lócus de um importante foco da doença.
Os achados concordam com a literatura sobre ocorrência de PFE em relação a sexo e ao contato com mercúrio, e sugerem significativa associação entre a ocorrência da doença e o contato com barragem de rejeitos de mineração, ainda não apontada em outros estudos.

Há que se considerar como limitação do estudo a impossibilidade de composição de um grupo mais numeroso de não portadores de PFE. No entanto, em que pese tal limitação, a ausência de diferenças significativas entre os grupos relativas a parâmetros tais como sexo, idade, escolaridade e acesso a planos de saúde, e o fato de serem todos parentes consanguíneos e habitarem o mesmo domicílio dos portadores da doença permitiu que associações entre PFE, histórico clínico-ocupacional e exposições ambientais fossem avaliadas com o mínimo de interferentes.

Os resultados também indicam a necessidade de vigilância epidemiológica eficaz das comunidades afetadas pela exposição aos fatores de risco para PFE, como mercúrio e rejeitos de mineração, em especial das populações atingidas pelos rejeitos liberados após o rompimento da barragem de Fundão, em novembro de 2015. Esta barragem está situada na mesma área de abrangência das mineradoras instaladas nas proximidades de Antônio Pereira e possui perfil de rejeitos semelhante ao da barragem de Doutor, citada neste estudo.

\section{REFERÊNCIAS}

1. Robledo MA, Emery DJ, Diaz LA, Fairle JÁ, López A, Taylor AF, et al. Chronic methyl mercury poisoning may trigger endemic pemphigus foliaceus "fogo selvagem". Med Hypotheses. 2012;78(1):60-6. PMid:22000710. http:// dx.doi.org/10.1016/j.mehy.2011.09.041.

2. Cunha PR, Barraviera SRCS. Dermatoses bolhosas auto-imunes. An Bras Dermatol. 2009;84(2): 111-124.

3. Bystryn JC, Rudolph JL. Pemphigus. Lancet. 2005;366(9479):61-73. PMid:15993235. http://dx.doi.org/10.1016/S0140-6736(05)66829-8.

4. Pavoni DP, Roxo VMMS, Marquart Fo A, Petzl-Erler ML. Dissecting the associations of endemic Pemphigus Foliaceus (Fogo Selvagem) with HLADRB1 alleles and genotypes. Genes Immun. 2003;4(2):110-6. PMid:12618858. http://dx.doi.org/10.1038/sj.gene.6363939.

5. Piovezan BZ. Susceptibilidade ao pênfigo foliáceo e o polimorfismo de genes da família NLR [dissertação]. Curitiba: Universidade Federal do Paraná; 2011.

6. Culton DA, Qian Y, Li N, Rubenstein D, Aoki V, Filhio GH, et al. Advances in pemphigus and its endemic pemphigus foliaceus (Fogo Selvagem) phenotype: a paradigm of human autoimmunity. J Autoimmun. 2008;31(4):311-24. PMid:18838249. http://dx.doi.org/10.1016/j.jaut.2008.08.003.

7. Friedman H, Campbell I, Rocha-Alvarez R, Ferrari I, Coimbra CE, Moraes JR, et al. Endemic pemphigus foliaceus (fogo selvagem) in native Americans from Brazil. J Am Acad Dermatol. 1995;32(6):949-56. PMid:7751464. http://dx.doi.org/10.1016/0190-9622(95)91330-0.
8. Pimentel LCF. Perfil sociodemográfico e distribuição dos casos de pênfigo foliáceo endêmico nas diferentes regiões do estado de Minas Gerais, no período de 2005 a 2006 [dissertação]. Belo Horizonte: UFMG; 2008.

9. Abréu AM. Pénfigo foliáceo endêmico: situación en Colombia. Acta Médica Colombiana. 1996;21(1):27-34.

10. Chaves SM, Netto JCA. Endemic pemphigus foliaceus: social and demographical characteristics and incidence in the microregions of Goias, based on patients seen at the Tropical Diseases Hospital, Goiania - Goias. An Bras Dermatol. 2005;80(3):261-6.

11. Brown MV. Fogo selvagem (pemphigus foliaceus): review of the Brazilian Literature. AMA Arch Derm Syphilol. 1954;69(5):589-99. PMid:13147566. http://dx.doi.org/10.1001/archderm.1954.01540170059008.

12. Chiossi MPV, Roselino AMF. Endemic Pemphigus foliaceus ("Fogo selvagem"): a series from the Northeastern region of the State of São Paulo, Brazil, 1973-1998. Rev Inst Med Trop S Paulo. 2001;43(2):59-62.

13. Hans-Filho G, Santos V, Katayama JH, Aoki V, Rivitti EA, Sampaio SAP, et al. An Active Focus of High Prevalence of Fogo Selvagem on an Amerindian Reservation in Brazil. The Cooperative Group on Fogo Selvagem Research. J Invest Dermatol. 1996;107(1):68-75. PMid:8752842. http://dx.doi.org/10.1111/1523-1747.ep12298213.

14. Aoki V, Rivitti EA, Diaz LA. Update on fogo selvagem, an endemic form of pemphigus foliaceus. J Dermatol. 2015;42(1):18-26. PMid:25558948. http://dx.doi.org/10.1111/1346-8138.12675. 
15. Vélez AMA, Warfvinge G, Herrera WL, Vélez CEA, Montoya MF, Hardy $\mathrm{DM}$, et al. Detection of mercury and other undetermined materials in skin biopsies of Endemic Pemphigus Foliaceus. Am J Dermatopathol. 2003;25(5):384-91. PMid:14501287. http://dx.doi.org/10.1097/00000372200310000-00004

16. Goldman M, Druet P, Gleishmann E. TH2 cells in systemic autoimmunity: insights from allogeneic diseases and chemically induced autoimmunity.
Immunol Today. 1991;12(7):223226. PMid:1832281. http://dx.doi. org/10.1016/0167-5699(91)90034-Q.

17. Pelletier L, Pasquier R, Rossert J, Vial MC, Mandet C, Druet P. Autoreactive T cells in mercury-induced autoimmunity. Ability to induce the autoimmune disease. Journal of Immunology. 1988;140(3):750-4.

Recebido em: Out. 06, 2016 Aprovado em: Maio 07, 2017 